\title{
Categorical phenomenalism about sexual orientation*
}

\author{
T. R. Whitlow | N. G. Laskowski ${ }^{\#}$ (1) \\ California State University, Long Beach
}

\section{Correspondence}

T. R. Whitlow, California State University, Long Beach.

Email: tannerrourkewhitlow@gmail.com

N. G. Laskowski, California State

University, Long Beach.

Email: ngl.philosophy@gmail.com

\footnotetext{
${ }^{*}$ Thanks to Kyle Bollin, Amanda Bryant, Jen Foster, Uriah Kriegel, and Dan López de Sa for written feedback on previous drafts. Thanks also to Michael Lara and participants at the Barcelona Seminar in Social Metaphysics on 28 May 2021 for their verbal feedback. We are grateful, too, for the comments that we received from an anonymous referee at this journal. ${ }^{\text {\#}}$ Some of the ideas for this paper began their development in a seminar on sexuality taught by Laskowski in Summer 2018 at Universität Duisburg-Essen. Many of these ideas were arrived at independently by Whitlow in their undergraduate honors thesis written under Laskowski's supervision during the 2019-2020 academic year. Every idea in this publication was made sharper by Whitlow. Whitlow and Laskowski extracted a part of Whitlow's thesis and began collaborating on the first ancestor of this publication when Whitlow began pursuing an MA at California State University, Long Beach in Fall 2020. While both authors contributed equally to
}

\begin{abstract}
What is sexual orientation? The contemporary consensus among philosophers is that it is a disposition. Unsurprisingly, recent debates about the metaphysics of sexual orientation are almost entirely intramural. Behavioral dispositionalists argue that sexual orientation is a disposition to behave sexually. Desire dispositionalists argue that it is a disposition to desire sexually. We argue that sexual orientation is not best understood in terms of dispositions to behave or dispositions to desire before arguing that dispositions tout court fail to illuminate sexual orientation. We then introduce and defend the idea that sexual orientation is best understood in terms of categorical phenomenal properties of sexual arousal.

\section{KEYWORDS}

behavior, desire, dispositions, phenomenal experience, sexual orientation
\end{abstract}


the conceptualization and writing of this publication, Whitlow's enthusiasm sparked this collaborative project and sustained its momentum to completion.

\section{1 | INTRODUCTION}

Try to recall the moment when a friend said to you, explicitly, that they were gay, straight, or bisexual. What did you learn about this person when they shared their sexual orientation? Perhaps you learned that there is something about them that explains why they have a certain kind of sexual history, e.g., something such that they've only had sex with men, only with women, sometimes with men and others times women, and so on. ${ }^{1}$ Perhaps you also learned that there is something about them in virtue of which they are more likely to enter into sexual relationships with men, women, etc. in the future. Our aim in this paper is to develop a view about the nature of this something - it is to introduce and defend a view about the metaphysics of sexual orientation.

In Sections 2 and 3, we argue against various permutations of the philosophically orthodox idea defended by Stein (1999) and more recently Dembroff (2016), Stock (2019), and Díaz-León (forthcoming), that sexual orientation is a disposition. In Section 4, we sketch a version of nondispositionalism about sexual orientation. In particular, we develop the categorical view that, roughly put, what it is for a person to be sexually oriented is for them to phenomenally experience sexual arousal in virtue of the features constitutive of a person's manhood, womanhood, and so on. In Section 5, we anticipate several objections to our view and reply to them. In short, sexual orientation is not, as many philosophers would have us think, a matter of how you would behave sexually or even how you would desire sexually; rather, it is a matter of the sexual arousal that you, as you are, feel.

\section{1 | Methodological preamble}

Sexual orientation has long been a topic of theoretical inquiry outside of Anglophone, analytic academic philosophy. Only recently has it received explicit and sustained attention among Anglophone analytic philosophers. ${ }^{2}$ Among these philosophers, it is common to theorize about sexual orientation at the level of concepts or at the representational level - about the sortals that acquaint us cognitively with the phenomenon of sexual orientation rather than the phenomena denoted at the level of properties, relations, states of affairs, and so on. ${ }^{3}$ Moreover, at the level of concepts,

\footnotetext{
${ }^{1}$ A note on our use of terms like 'man', 'male', 'woman', 'female', etc. We're sympathetic to the view that they are polysemous in the sense that they have multiple related meanings just as “...pretty much any ordinary noun, adjective, or verb..." (Fogal 2016: 285). In particular, we're sympathetic to the view that these terms are sometimes used to express an anatomical meaning (i.e., used as "sex" or "biological" terms), sometimes used to express a non-anatomical meaning (i.e., used as "gender" or "social” terms), and sometimes used to express still other meanings. See Saul (2012), Bettcher (2014), Diaz-Leon (2016), Laskowski (2020), and Zeman (2020) for related discussion.

${ }^{2}$ In addition to the references found in the introduction, other recent work includes Wilkerson (2009, 2013), Bettcher (2014), Ayala (2017), Díaz-León (2017), Brunning \& McKeever (2020), Finocchiaro (2021, manuscript), and Andler (2021, forthcoming).

${ }^{3}$ See especially Dembroff (2016), Díaz-León (forthcoming), and Andler (forthcoming).
} 
many of these philosophers aim to engineer a concept of sexual orientation rather than merely analyze such a concept. ${ }^{4}$

We think that the project of conceptually engineering a concept of sexual orientation is an intriguing and worthwhile one. ${ }^{5}$ But it is not our project. Instead, we aim to offer an analysis of the relational property is sexually oriented to or a real definition of it. ${ }^{6}$ It takes the following form:

Sexual orientation schema What it is for a man, woman, etc. $x$ to be sexually oriented to a man, woman, etc. $y$ is for $x$ to... in virtue of the features that constitute $y$ 's manhood, womanhood, etc.

In this schema, ' $x$ ' and ' $y$ ' stand for arbitrary men, women, etc. and the ellipsis serves as a placeholder for a part of a property that illuminates the metaphysics of sexual orientation. We recognize that these methodological assumptions are contestable. We also recognize that our approach commits us to a number of substantive claims about sexual orientation. ${ }^{7}$ We urge our readers to bear with us as we show that there is value, at least arguendo, in making such assumptions and begging various questions.

\section{2 | SEXUAL DISPOSITIONS AND BEHAVIORS}

One way for a philosopher to risk getting themselves into trouble with their colleagues is to paint a philosophical debate with too broad a brush. But when it comes to the nature of sexual orientation, it's safe to say that most philosophers working on the metaphysics of sexual orientation have defended dispositionalism or the view that, schematically put:

Dispositionalism What it is for $\mathrm{x}$ to be sexually oriented to $\mathrm{y}$ is for $\mathrm{x}$ to be disposed to manifest $\mathrm{m}$ in relation to $\mathrm{y}$ in stimulating circumstance $\mathrm{c}$, where $\mathrm{x}$ is disposed to manifest $\mathrm{m}$ iff, if $\mathrm{x}$ were in $\mathrm{c}, \mathrm{x}$ would manifest $\mathrm{m} .^{8}$

Typically, the case for dispositionalism is made by appealing to its predictions about cases. Consider an open-minded, honest, and middle-aged man who has spent his life engaging sexually only with women until he ends up in prison where he starts to engage with other men. ${ }^{9}$ In virtue of his open-mindedness and self-directed honesty, he has led a rich life of sexual exploration. He thereby knows himself well enough to know that he's sexually oriented to women. But he

\footnotetext{
${ }^{4}$ See Finlay and Laskowski (2017) for a recent breakdown of what we're doing when we're doing conceptual analysis in metaethics that is helpful in sorting out what we're doing when doing conceptual analysis generally. See Burgess, Plunkett, and Cappelen (2020) for a detailed overview and collection of papers on conceptual engineering.

${ }^{5}$ Conceptual engineering as such has received considerable and rigorous attention over the last decade or so, but some argue (See Cappelen 2018 for a book-length defense) that conceptual engineering is what philosophers have been more or less up to all along since at least Frege and Carnap.

${ }^{6}$ See Wedgwood (forthcoming) for a useful recent discussion of the kind of approach we favor as it is applied in metaethics.

${ }^{7}$ For example, it commits us to the claim, shared by Díaz-León (forthcoming) and Andler (forthcoming), that sexual orientation is reflexive in the sense that manhood, womanhood, etc. figures in both sides of the analysis. Dembroff (2016) argues that sexual orientation is best understood irreflexively.

${ }^{8}$ See Stein (1999), Dembroff (2016), Stock (2019), and Díaz-León (forthcoming) for defenses of dispositionalism.

${ }^{9}$ Our choice of examples is influenced in part by the choice of examples that appear in other important work on sexual orientation, e.g., prisons are mentioned in Dembroff (2016).
} 
still has sexual needs as a human and there's no end in sight to his time in prison. Because the man would engage sexually with women were he in the relevant circumstances, dispositionalism makes the seemingly correct prediction that the man is sexually oriented to women despite the fact that his actual circumstances are such that for the time being, he has sex with other men. ${ }^{10}$

Dispositionalism is a big tent. We can slot in different manifestation or circumstance values to yield a variety of dispositionalist views. One influential view slots in behavior as the relevant manifestation, which gives us the following view:

Behavioral Dispositionalism What it is for $\mathrm{x}$ to be sexually oriented to $\mathrm{y}$ is for $\mathrm{x}$ to be disposed to engage in sexual behaviors in relation to y in circumstance c. ${ }^{11}$

While behavioral dispositionalism is also motivated by cases, it's also often motivated by demonstrations of the failure of behaviorism about sexual orientation or the view that what it is for $\mathrm{x}$ to be sexually oriented to $\mathrm{y}$ is for $\mathrm{x}$ to engage in observable sexual behavior with $\mathrm{y} .{ }^{12}$ This is somewhat curious since few philosophers have defended behaviorism about sexual orientation. ${ }^{13}$ We trust the reader to sort out why for themselves. ${ }^{14}$ All the same, it's not necessary to contrast behavioral dispositionalism with behaviorism's failure to see why philosophers are attracted to the former. Sex is often something we do, but not, of course, something we always do. It's a short step from this observation to the idea that what it is to be oriented sexually involves, in some way, potential sexual behavior. ${ }^{15}$

We think that behavioral dispositionalism enjoys much more prominence than it deserves. Indeed, we think that both parts of the view, the behavioral part and the dispositional part, ought to be rejected. We'll argue against the dispositional part later on. Focus on the behavioral part for now.

Here's our first of three objections to behavioral dispositionalism. Consider the case of Hank, a man who is paraplegic. ${ }^{16}$ He has no feeling below his neck and cannot use his arms or hands. Hank also has no sexual function in his genitals and he has problems with breathing and swallowing. Thus, Hank cannot engage in any sexual behavior, including sexual behavior that is

\footnotetext{
${ }^{10}$ Perhaps dispositionalism also predicts that the man is sexually oriented to men. Perhaps, too, that's not the correct prediction. It's enough for us to justify exploring the view in detail that it at least makes the intuitively correct prediction that the man is sexually oriented to women.

${ }^{11}$ See Dembroff (2016) and Stock (2019).

12 See Stein (1999), Dembroff (2016), and Díaz-León (forthcoming).

${ }^{13}$ Thanks to a referee from this journal for reminding us that Foucault (1980) can be read as defending a view in the ballpark of behaviorism about sexual orientation. We note, however, that the aforementioned authors do not attribute this view to Foucault or any other philosopher.

${ }^{14}$ Or they can have a look at work from the aforementioned authors. They make a strong case against behaviorism about sexual orientation.

${ }^{15}$ While some of what we say later on in this paper could be used by a behaviorist to improve the view, other considerations that we enlist ultimately count more strongly against even improved versions.

${ }^{16}$ We do not use cases involving disabled individuals lightly. We recognize that using such cases risks objectifying disabled people. But such risks are arguably objectionable only when such discussions are sufficiently divorced from what disabled and other marginalized communities report about their own lives. It is perhaps also worth noting that one of us, the authors of this piece, belong to that very community. Relatedly, in this spirit, see Schneider, et al. (2002) for a discussion of the case of a man who discovered his sexual orientation only years after a traumatic brain and spinal cord injury that left him with no feeling below the waist and an inability to ever engage sexually with men, or anyone else.
} 
performed with his hands or mouth. Hank is also congenitally paraplegic, so he has never engaged in any of these sexual behaviors. Nevertheless, Hank claims to be sexually oriented to men and he's married to a man. Hank has no disposition to engage in sexual behaviors due to his disability. Consequently, on behavioral dispositionalism, Hank lacks a sexual orientation. This seems false. A disability that prevents someone from engaging in sexual activity doesn't preclude that person from having a sexual orientation. Being disposed to engage in sexual behavior is not a necessary condition on sexual orientation.

Here's another objection to behavioral dispositionalism. Consider Zombie Hank, who is like Hank in that he claims to be sexually oriented to men and is married to a man. However, Zombie Hank is unlike Hank in at least two ways. First, Zombie Hank has no physical disabilities. Indeed, Zombie Hank is disposed to engage in various sexual behaviors with his husband, using his hands, mouth, and so on. Second, Zombie Hank lives up to his name in that he is congenitally incapable of having phenomenal experiences, including phenomenal experiences of sexual arousal. Like zombies of philosophical lore generally, Zombie Hank cannot experience the sourness of a sour IPA or thrill of rock climbing. Because Zombie Hank cannot have these experiences, it is a mistake to claim that Zombie Hank is a beer lover or rock-climbing enthusiast, even if he is somehow disposed to go to the bar or climb rocks. Likewise, because Zombie Hank cannot have phenomenal experiences of sexual arousal, it is a mistake to claim that Zombie Hank has a sexual orientation, even if he is disposed to engage in various sexual behaviors. But behavioral dispositionalism makes just this mistake, predicting that Zombie Hank has a sexual orientation when he doesn't. Hollywood depictions notwithstanding, Zombies do not have sexual orientations. The case of Zombie Hank casts doubt on the behavioral dispositionalist commitment that being disposed to engage in sexual behaviors is a sufficient condition on having a sexual orientation.

We do not pretend that these two objections to behavioral dispositionalism are sophisticated. They are simple counterexamples, after all. But sometimes less is more and we claim that this is one of those times. Of course, however, there are a number of replies available to the behavioral dispositionalist. We'll now discuss three before turning to our third objection. The first is as simple as our first two objections. Some have responded to Hank's case by suggesting that if we have a sufficiently broad understanding of "behavior", one that includes "visual behavior" like watching his husband undress or "linguistic behavior" like verbalizing his interest in being touched, then behavioral dispositionalism yields the correct verdict that Hank has a sexual orientation.

We have two responses. First, we suspect that a version of behavioral dispositionalism that invokes a sufficiently broad notion of "behavior" either over generates or relies on an unprincipled distinction between behavior and non-behavior. Second, broad behavioral dispositionalism, as it were, fails to make the correct prediction about a variation of a case involving Hank. Imagine that in addition to being congenitally disabled as described above, Hank becomes visually and linguistically disabled later in life. Broad behavioral dispositionalism predicts that Hank loses his sexual orientation immediately. That's implausible.

There's another, more sophisticated response to our extensional objections. It starts with the idea that it is a constraint on the very subject matter of sexual orientation that only people who are willing and able to engage in sexual behaviors can instantiate the property of being sexually oriented. ${ }^{17}$ Hank's congenital disability means that he's never had a disposition to engage in sexual behavior, so Hank's case isn't, on this line of thought,

\footnotetext{
${ }^{17}$ This constraint takes inspiration from Dembroff (2016: 17, emphasis ours) “The operative concept [of sexual orientation] assumes that one is willing and able to sexually engage with other persons."
} 
even about sexual orientation. Whatever properties Hank instantiates, they aren't sexual orientation properties. Just as one might think that cases involving non-human animal predators causing prey to suffer can't tell us anything about moral responsibility (because non-human animals can't engage in the space of reasons), one might think that Hank's case can't tell us anything about sexual orientation (because he can't engage in sexual behavior).

The general form of this objection seems to rely on the idea that if it's impossible for something to instantiate a property, then facts about that thing are not probative with respect to the nature of the property. We can begin to see why this general form of argument rests on a mistaken idea by considering a paradigmatic case of a dispositional property. ${ }^{18}$ Fragility is often said to be a disposition that something possesses when it breaks in response to being struck without great force. Things that are fragile include wine glasses, cell phone screens, and our egos when we receive desk rejections from journals. All of these things are fragile because they are easily broken. Now suppose that it is metaphysically impossible for anything to break. Plausibly, if nothing can break, then nothing can be fragile. Indeed, it seems that the manifestation type, breaking, is explanatorily prior to the disposition type, fragility - there can be breaking without fragility but not fragility without breaking. ${ }^{19}$

Notice, however, that at no point in reflecting on the above possibilities and impossibilities did the subject matter of the discussion - the nature of the dispositional property of fragility - change. In fact, it was reflection upon the impossibility of breaking that encouraged an interesting conjecture about the explanatory priority of fragility and breaking. Likewise, Hank's case encourages various thoughts about the explanatory priority of sexual behavior and sexual orientation. It's just not true that Hank's case is a red herring or non sequitur. But if that's right then it seems like a mistake to claim that Hank's case cannot even be relevant to a discussion of the nature of sexual orientation because Hank's case isn't even about sexual orientation.

Our response to the behavioral dispositionalist's subject-matter objection, as it were, foregrounds another objection on behalf of the behavioral dispositionalist. Grant that cases like Hank's case are relevant to discussions of the nature of sexual orientation. Perhaps the above scenario involving the impossibility of breaking establishes that the manifestation type, breaking, is explanatorily prior to the disposition type, fragility. Taking inspiration from this thought, the behavioral dispositionalist might then say that Hank's case shows, similarly, that the manifestation type, sexual behavior, is explanatorily prior to the disposition type, being sexually oriented to. What Hank's case doesn't show, on this line of response, is that sexual orientation doesn't involve sexual behavior. Or so the behavioral dispositionalist might argue.

We have two responses. While it is possible that the manifestation type, sexual behavior, is explanatorily prior to the disposition type, being sexually oriented to, the behavioral dispositionalist is still committed to saying that Hank doesn't have a sexual orientation because he isn't nor can he be disposed to engage in sexual behavior. However, it's still plain to us that Hank has a sexual orientation. Consequently, behavioral dispositionalism still ought to be rejected. Second, and moreover, as we'll see in a moment, even granting, arguendo, that sexual behavior is explanatorily

\footnotetext{
${ }^{18}$ We also happen to think that the response is worryingly ableist. Shah (2017) gives us reason to be cautious about discounting the personal testimony of disabled people in discussions about sexual orientation. Disabled people are often desexualized despite being sexual beings in their own assertions. If we listen to able-bodied personal testimony with regard to sexual phenomenology, we should listen to disabled people as well.

${ }^{19}$ This line of response is inspired by Elliot (2017).
} 
prior to being sexually oriented to, we'll provide evidence for thinking that another, non-behavioral type explanatorily precedes sexual behavior, and hence that sexual behavior doesn't provide the most fundamental explanation of sexual orientation.

We can imagine several other kinds of sophisticated responses to our use of Hank's case in our first objection to behavioral dispositionalism. Perhaps most saliently, the behavioral dispositionalist might now be tempted to insist that Hank really is disposed to behave sexually, it's just that his disposition is being masked by his paraplegia. ${ }^{20}$ Compare a ceramic mug being delivered to your house in a box filled with foam peanuts. Intuitively, the mug is still fragile in the sense of being disposed to break even though it won't break due to interference from the peanuts. Thus, on this line of response, Hank is not a counterexample to behavioral dispositionalism.

Notice, however, that Hank's case is an important way unlike the mug case - Hank is congenitally paraplegic. It is an intrinsic feature of Hank that he is paraplegic. Consequently, whether his paraplegia masks his sexual orientation depends on the possibility not just of masking, but of intrinsic masking. For example, one might be tempted to say that peyote cacti are disposed to manifest hallucination but that the surface of the cacti's crown, an intrinsic feature of such cacti, stops the manifestation. Maybe that's the right thing to say about cacti, so maybe it's also the right thing to say about Hank. We're skeptical. ${ }^{21}$ At any rate, we hope readers will agree that we cannot be expected in the span of a paper about the particular metaphysical issue of sexual orientation's nature to settle these vexed and seemingly intractable general metaphysical debates about whether dispositions can be intrinsic ${ }^{22}$, whether masks can be intrinsic ${ }^{23}$, whether intrinsic dispositions can be intrinsically masked, and so on.

Nevertheless, for those readers who find intrinsic masking plausible, we offer a third and final objection to behavioral dispositionalism that, we claim, provides decisive reason to search for an alternative view. This second objection starts with the observation that dispositions to behave in general and dispositions to behave sexually in particular don't just appear out of thin air. Dispositions to behave sexually aren't brute. We can intelligibly ask: Why are we disposed to behave sexually?

Plausibly, when we are disposed to behave sexually, that's because some further feature(s) of us grounds the behavioral disposition, such as our dispositions to want to behave sexually, our disposition to be curious about what some kind of sexual behavior would feel like, our dispositions to hope that behaving sexually will achieve some aim, and so on. These mentalistic dispositions appear to explain why we are disposed to behave sexually. But if that's right then dispositions to behave sexually do not provide an explanation of sexual orientation at the most fundamental level. At most, dispositions to behave sexually provide an intermediary explanation in the hierarchy of explanatory fundamentality. Dispositions to be in various mental states, such as desire, curiosity, and hope, appear to explain our

\footnotetext{
${ }^{20}$ See Johnston (1992).

${ }^{21}$ We're skeptical of intrinsic masking in general as it seems to license a host of implausible negative ability attributions. If things intrinsic to us can make it the case that dispositions are being masked, then it seems that things have an incredible number of dispositions that never manifest on account of masking. That strikes us as implausible. But even if we grant intrinsic masking, it still doesn't seem like Hank is a good candidate for it. Hank is congenitally paraplegic. He's just not of the kind that engages in sexual behaviors. Just like a caterpillar has no disposition to cook its food, neither does Hank have the disposition to engage in sexual behaviors.

${ }^{22}$ See Lewis (1973).

${ }^{23}$ See Ashwell (2010).
} 
dispositions to behave sexually, and so provide a more fundamental explanation of sexual orientation. ${ }^{24}$

Our first two objections to behavioral dispositionalism provide strong reason to ditch the behavioral bit of behavioral dispositionalism. Our third objection provides strong reason to replace behavior as the relevant manifestation value with an alternative, more mentalistic value. In the next section, we explore an alternative form of dispositionalism that takes our three objections seriously.

\section{3 | DISPOSITIONS AND DESIRES}

Previously, we introduced the idea that sexual orientation can be understood as a dispositional property. We noted that we get different dispositionalist views depending on the values we slot in for the relevant manifestation and circumstance values in the dispositional analysis. Much of the previous section was spent arguing that there is good reason not to analyze sexual orientation in terms of dispositions to behave sexually. Indeed, we argued that there is good reason to think that insofar as dispositions figure in the correct analysis of sexual orientation, it's our dispositions to have various mental states. Together with the truism that sex is importantly related to wanting or desiring, we are led to explore a potentially more promising form of dispositionalism in this section that we call:

Desire Dispositionalism What it is for $\mathrm{x}$ to be sexually oriented to $\mathrm{y}$ is for $\mathrm{x}$ to be disposed to sexually desire y in circumstance $\mathrm{c}^{25}$

We can begin evaluating desire dispositionalism by noting that it predicts the right results about cases that have come up in our discussion. The man in prison who sees himself as sexually oriented to women is, on desire dispositionalism, sexually oriented to women because he is disposed to sexually desire women. Hank, a man who seems himself as sexually oriented to men and who is not disposed to engage in sexual behavior due to congenital paraplegia, is disposed to sexually desire men. Thus, on desire dispositionalism, Hank is sexually oriented to men. Replacing dispositions to sexually behave with dispositions to sexually desire as the relevant manifestation type has promise. Desire dispositionalism is off to an auspicious start.

However, we think the following three objections make a powerful case against desire dispositionalism. The first is another extensional objection involving Zombie Hank. Recall, Zombie Hank claims to be sexually oriented to men and married to a man. Zombie Hank is also congenitally incapable of having a phenomenal experience of sexual arousal. In addition to being behaviorally disposed to engage sexually with men, we can add that Zombie Hank is disposed to desire to have sex with men. Desire dispositionalism predicts that Zombie Hank is sexually orientated to men. But Zombie Hank does not feel sexually aroused by men or feel any sexual arousal at all. ${ }^{26} \mathrm{He}$ does not feel his heart race at the sight of another man. Nevertheless, desire

\footnotetext{
${ }^{24}$ This is the reply to the claim that the type sexual behavior is explanatorily prior to the type being sexually oriented to that we promised above.

${ }^{25}$ One high-profile proponent of this kind of view is Díaz-León (forthcoming).

${ }^{26}$ See Smith (1994) for a defense of a non-phenomenological account of desire. See also Arpaly and Schroeder (2014: Chapter 6).
} 
dispositionalism predicts that Zombie Hank is sexually oriented to men. We think that's implausible. Being disposed to desire sexually is not a sufficient condition for having a sexual orientation.

Our second objection to desire dispositionalism is also an extensional one. On desire dispositionalism, being disposed to desire sexually is a necessary condition on having a sexual orientation. But imagine a woman who experiences the phenomenal feeling of sexual arousal around women but who lives in an overwhelmingly oppressive patriarchal society that forbids sexual relationships between women. Imagine, too, that this person has managed, sadly, to rid themselves of all their sexual desires for women out of a sense of self-preservation. ${ }^{27}$ Desire dispositionalism predicts that this woman is not sexually oriented to women. We think that's implausible.

Our third objection goes beyond extensional worries. Vindicating desire dispositionalism, or any form of dispositionalism, for that matter, requires defending not just a view about the relevant manifestation types, but also a view about the circumstances or conditions under which the dispositions are said to manifest. A fault line concerning the nature of the conditions under which dispositions are said to manifest has emerged among proponents of dispositional views. On one hand, we might say that the relevant conditions under which our dispositions to sexually desire manifest are "ideal" conditions where we can understand conditions to be ideal when "there are no forces to prevent or discourage a person from acting on his or her [sexual] desires that is, when there is sexual freedom and a variety of appealing sexual partners available". ${ }^{28}$ On the other hand, we might say that the relevant conditions are "ordinary" in the sense that they are not ideal. $^{29}$

Dispositionalists tend to favor ordinary over ideal conditions. ${ }^{30}$ This is, it seems, mostly attributable to the apparent strength of arguments against ideal conditions. One influential argument starts with the idea that the ideal conditions themselves might obstruct the manifestation of our dispositions to sexually desire in precisely the way that ideal conditions are meant to eliminate. ${ }^{31}$ Consider ideal desire dispositionalism or the view that what it is for $\mathrm{x}$ to be sexually oriented to $\mathrm{y}$ is for $\mathrm{x}$ to be disposed to sexually desire $\mathrm{y}$ in ideal conditions in which there is sexual freedom and a variety of appealing sexual partners available. This view tells us that if you want to determine that a person has a sexual orientation and what kind of sexual orientation, go to a world in which there is sexual freedom and a variety of appealing sexual partners available and check to see whether and how their dispositions to sexually desire manifest.

Silvia, for example, is a woman who has only ever engaged sexually with men. She also has dispositions to sexually desire women that have never manifested. We can imagine that this is because she lives in an environment in which there are no women sexual partners available. It's a fact about Silvia that if she weren't in such an environment, her dispositions to

\footnotetext{
${ }^{27}$ It might not be possible for creatures like us in a world like ours to feel arousal without the corresponding desire. But we suspect otherwise. It seems to us that something could interfere with a causal relationship between a feeling of arousal and a corresponding desire in a creature like us in a world like ours, at least. In any case, it seems in principle possible for an entity to experience arousal without desire.

${ }^{28}$ This comes from Stein (1999: 45).

${ }^{29}$ See Dembroff (2016: 14-17).

${ }^{30}$ Díaz-León (forthcoming) rebuts one of Dembroff's arguments against ideal conditions but in the end seems not to endorse ideal conditions.

${ }^{31}$ See Dembroff (2016: 15) and Finocchiaro (manuscript, 6).
} 
sexually desire women would manifest. It's intuitive to say that Silvia has a sexual orientation - she is oriented to men and women or women. Ideal desire dispositionalism predicts that result. Moreover, it seems to do so precisely because it tells us that the conditions for the manifestation of one's disposition to sexually desire are those in which there is no, as it were, obstructions.

But ideal conditions can be turned on their head. Now imagine that Silvia is prone to decision fatigue in the sense that when she is confronted with too many options she freezes up. Compare the situation to deciding on what to eat at a restaurant with a bloated menu. In ideal conditions, there are plenty of sexual partners who are women available. But when facing a plethora of potential sexual partners, Silvia cannot form desires or make up her mind more generally. So, in ideal conditions, Silvia's dispositions to desire manifest in bizarre ways if at all. Consequently, on this line of objection, we cannot learn anything about an individual's sexual orientation by reflecting on how one's sexual desires would manifest in ideal conditions. Thus, we ought not to understand those conditions as ideal conditions. ${ }^{32}$

Perhaps we ought to understand the relevant conditions as ordinary conditions instead. We doubt it. Imagine a different version of Silvia's case where she is still prone to decision fatigue but where the "ordinary" conditions that Silvia inhabits are conditions in which there is a wide variety of available sexual partners who are women. Consequently, in these conditions, Silvia's dispositions to sexually desire women do not manifest. However, in "ideal" conditions, where there is not a wide range of available sexual partners who are women, Silvia's dispositions to sexually desire manifest. Proponents of the above objection to ideal conditions would have us say that the manifestation of Silvia's dispositions to sexually desire in these "ideal" conditions where there is not a wide variety of sexual partners are not relevant - they don't tell us about Silvia's sexual orientation. We don't see why. ${ }^{33}$

It seems to us that there is no clean line to be drawn between so-called "ordinary" and "ideal" conditions. Indeed, Silvia's situation strongly suggests that there is no non-arbitrary way to determine which conditions theoretically matter to an analysis of sexual orientation. Because we are pessimistic about the prospects of ever informatively characterizing such conditions, we conclude that there is strong reason to reject all dispositional analyses of sexual orientation. In the next section, we begin to develop an alternative, non-dispositional analysis of sexual orientation. ${ }^{34}$

\footnotetext{
${ }^{32}$ A different lesson that one might draw from our objection is that we haven't identified which conditions are ideal. Perhaps what we should take away from Silvia's case is that ideal conditions are those where a variety of sexual partners are available and where decision fatigue isn't experienced. Going this route is an option. But as we go on to suggest we ultimately suspect that there isn't any non-arbitrary way to identify one set of conditions as "ideal" over another.

${ }^{33}$ It might help to think of our concerns from the perspective of Shope's (1978) influential discussion of conditional analyses. Dispositional analyses are conditional analyses - they tell us what is the case by pointing to how things would be if some condition(s) were to hold. But how things would be if some condition(s) were to hold could depend on other conditions that actually obtain also being different. But these other differences might well make all the difference.

${ }^{34}$ One form of dispositionalism that we don't discuss is what we might call phenomenal dispositionalism, the view that what it is for $\mathrm{x}$ to be sexually oriented to $\mathrm{y}$ is for $\mathrm{x}$ to be disposed to phenomenally experience sexual arousal in response to $y$ in circumstance $\mathrm{c}$. This form of dispositionalism is closest to the view that we end up defending. Unsurprisingly, we see it as the most promising form of dispositionalism. However, like behavioral and desire dispositionalism, we think the prospects of informatively characterizing the relevant manifesting conditions on phenomenal dispositionalism are dim.
} 


\section{4 | SEXUAL ORIENTATION, CATEGORICALLY AND PHENOMENALLY UNDERSTOOD}

We've argued that existing views of the nature of sexual orientation, all of which are dispositional, ought to be rejected. Dispositional views are extensionally inadequate and fail to provide the most fundamental explanation of sexual orientation. They also rely on a dubious distinction concerning the manifestation conditions that are supposed to be relevant to the analysis. Our arguments point to views of sexual orientation that are non-dispositional or categorical and not behavioral and not desire based. In this section, we sketch such a view, illustrate some of its virtues, and clarify it by way of anticipating and rebutting objections. Here's the view:

Categorical Phenomenalism What it is for $\mathrm{x}$ to be sexually oriented to $\mathrm{y}$ is for $\mathrm{x}$ to phenomenally experience sexual arousal in response to $y$ in virtue of the features that constitute y's manhood, womanhood, etc.

This is a categorical, real definition of the relational property of being sexually oriented to because, roughly put, it specifies the property it is necessary and sufficient to actually exhibit to count as exhibiting sexual orientation. Again, in contrast, dispositional views are noncategorical in the sense that they specify counterfactual properties that it is necessary and sufficient for one to exhibit to count as exhibiting sexual orientation. Categorical phenomenalism specifies the categorical property that, at the most fundamental level in the explanatory chain of fundamentality, grounds any further dispositional properties to behave or desire sexually.

Categorical phenomenalism is a phenomenal analysis of sexual orientation because it tells us that it is necessary and sufficient for exhibiting sexual orientation that one experiences or feels sexual arousal. Such analysans are best appreciated by ostension to vividly described scenarios. But since neither of us have the literary skill to convey such experiences without making you cringe we urge you to pick up your favorite steamy romantic novel. Read one of the scenes involving passionate sex. Now check your pulse and turn your mind's eye inwards to scan the sensations that you're experiencing currently. Those feelings of sexual arousal are the ones that constitute your sexual orientation. ${ }^{35}$

Now, the passage(s) that you read from the romantic novel will have featured some combination of men, women, or non-binary protagonists. Assuming that manhood, womanhood, etc. are not best understood as sui generis entities, those men, women, etc. exhibit features that constitute their manhood, womanhood, etc. Perhaps it's the timbre of their voice, the shape of their bodies, their position in a social hierarchy, the desires they possess, and so on that constitute these features. Whatever those features are, it's your feeling of sexual arousal in response to those features that figure in categorical phenomenalism's analysis of sexual orientation. ${ }^{36}$

\footnotetext{
${ }^{35}$ One may argue that this fictional romance novel is not a good indicator of sexual orientation because people can be aroused by fictions that they would never actually be aroused by in real life. However, we don't claim that these fictional scenarios are indicators of any sort of orientation. We just want the reader to understand the sort of phenomenological feeling we are calling sexual arousal and it is easier to access your favorite fictional sexual scenarios than a real one, in most cases.

${ }^{36}$ In other words, we are following other sexual orientation theorists, like Dembroff (2016) and Díaz-León (forthcoming, 2017) in distinguishing sexual preference from sexual orientation and affirming that the latter only involves features constitutive of manhood, womanhood, etc.
} 
A natural way to demonstrate the view's promise is to illustrate how it yields intuitively correct predictions about cases that have figured in this paper. In the case of the man in prison, even though he willingly engages in sexual activity with other men while constrained in his options, he still feels sexual arousal in response to women. Categorical phenomenalism predicts that he's sexually oriented to women. That's the right result. In the case of Hank, even though he cannot engage in sexual behaviors and has never engaged in sexual behaviors, he's still sexually oriented to men because he feels sexual arousal in response to other men. Categorical phenomenalism predicts that he's sexually oriented to men. That's the right result. Zombie Hank experiences no feelings of sexual arousal whatsoever. Categorical phenomenalism predicts that he has no sexual orientation. That's the right result. Though Silvia doesn't have many available sexual partners who are women, insofar as she experiences sexual arousal in response to those few in her orbit, categorical phenomenalism predicts that she is sexually oriented to women. That's the right result again.

Categorical phenomenalism also promises to offer the most fundamental explanation of sexual orientation. Plausibly, dispositions to behave sexually are grounded in the feeling of arousal to which those behaviors are aimed. Such behaviors are likely mediated by our sexual desires. But these desires are also plausibly explained by our feeling of sexual arousal. Why do you have sex with women? Because you want to have sex with them. Why do you want to have sex with them? Because those individuals make you feel sexually aroused. Why do you feel sexually aroused by them? It's hard to say anything more philosophically illuminating at this point, which indicates that we've reached the most fundamental level of philosophical explanation.

In addition to its extensional adequacy and explanatory fundamentality, categorical phenomenalism also has several other attractive features. For one, it seems to well capture the epistemology of sexual orientation. In order to know one's sexual orientation all one needs to know is whether they feel arousal in response to particular kinds of people. ${ }^{37}$ This makes it relatively easy for one to know their own sexual orientation. ${ }^{38}$ There is no need, as there is in dispositionalist views, to understand yourself so well that you know what you would do in an assortment of counterfactual scenarios under ideal or ordinary conditions. ${ }^{39}$

A related and interesting question concerns ascriptions of such knowledge - what exactly are we ascribing when we say things like 'Hank knows that he's sexually oriented to men'. Categorical phenomenalism is compatible with a range of answers to this question. Sorting through this range adequately merits a paper unto itself. But we think that categorical phenomenalism pairs well with what we'll call a direct specification of what is ascribed with knowledge ascriptions of sexual orientation rather than an indirect specification. Briefly put, on a direct specification, what is ascribed to Hank is that he knows that he experiences sexual arousal in response to short hair, broad shoulders, tendency to condescendingly explain, and so on, i.e., the features that constitute manhood. On the second, indirect specification, what is ascribed to Hank is that he knows that he experiences sexual arousal in response not to the features that constitute manhood, but to manhood itself - he cognizes manhood as such. We claim that sexual orientation ascriptions are best understood directly specified, because when one is sexually aroused by someone, they are not aroused by the fact that the object of their arousal falls under the category manhood, womanhood, etc. Instead, they are attracted to the features of people that make them members of these

\footnotetext{
${ }^{37}$ Of course, there are important debates about how we can know our own minds. See Ashwell (2013). But our claim isn't that it's easy to know one's mind, it's that it's easier than knowing how one would act in various counterfactual scenarios.

${ }^{38}$ Or at least no harder than it is to know whether someone is a man, woman, etc.

${ }^{39}$ According to Pelham (2004), people poorly predict what they would do and how they would feel in novel situations.
} 
categories, such as people with a certain set of genitalia, softer features, more facial hair, presence of breasts, etc. ${ }^{40}$ We are aroused by the underlying features not the higher-order metaphysical properties. $^{41}$

\section{5 | OBJECTIONS AND REPLIES}

Having outlined categorical phenomenalism and demonstrated its promise, we'll close out our discussion by anticipating and answering objections to it in an effort to further clarify its commitments.

Objection \#1: Categorical phenomenalism seems to say that you are sexually oriented when and only when you feel sexual arousal. But unless you are in a state of constant sexual arousal, categorical phenomenalism implies that you're sexually oriented only intermittently. Intuitively, however, being sexually oriented is a more stable property of persons. Consequently, we ought to reject categorical phenomenalism.

Reply: Categorical phenomenalism is an analysis of the property of being sexually oriented to. Distinguish this analysis from an analysis of the corresponding concept, which we claim is best understood as a kind of summary concept in the sense that it summarizes past instances of sexual arousal. ${ }^{42}$ Claiming that a person has a sexual orientation is to claim that they exhibited sexual arousal enough times previously to cross some (likely contextually determined) threshold. On this picture, the property of being sexually oriented is "stable" insofar as instances of it are repeated over time. It is less like the property of being a New Yorker and more like the property of being honest. Just as it is incorrect to say that a person is honest if they've never or only rarely acted honestly, it is incorrect to say that a person has a sexual orientation if they've never or only rarely experienced sexual arousal in response to features that constitute a person's manhood, womanhood, etc. ${ }^{43}$ Packaging categorical phenomenalism with these further claims allows us to accept the implication that the property is intermittent while denying that it's a problem. ${ }^{44}$

\footnotetext{
${ }^{40}$ This distinction might sound like the familiar de re/de dicto distinction. But that is a syntactic or semantic distinction concerning the scopal properties of quantified expressions. We think that what people tend to be after when they employ the language of de re/de dicto is closer to what we describe above - something about the psychological concepts deployed. Our way of thinking about this is helpfully informed by Howard (2021a).

${ }^{41}$ Some theorists, like Stock (2019) argue that such ascriptions should be understood "de dicto" because we can imagine scenarios in which someone learns that a woman was assigned a different gender at birth than what their presentation would suggest and based on that information lose their sexual desire for the person. But even if this happens, one does not merely learn that the individual once belonged to a different category - they learn that they had a whole host of different features that constitute being a member of the category. Consequently, such cases do not provide clear support for the "de dicto" reading.

${ }^{42}$ We take inspiration from similar observations about some normative concepts made originally by Foot (1978: 182) and taken up subsequently by Stratton-Lake (2000: 14), Dancy (2004: 16), and Howard (2021b: 2-3).

${ }^{43}$ Not everyone will find these analogies helpful, especially the analogy with honesty. What we say about honesty contrasts with Miller's (2021) prominent view of honesty and an influential view of personality traits more generally found in, inter alia, Brandt (1970: 26) and Miller (2014: 19-20). See, inter alia, Wiggins (1997) for an expression of a view more congenial to our own.

${ }^{44}$ One might worry that proponents of rival views, e.g., behavioral dispositionalists, can avail themselves of this move in response to our objections to their views. But behavioral dispositionalism still makes the wrong prediction that Hank doesn't have a sexual orientation even if the view were supplemented with the claim that the concept of sexual orientation summarizes previous manifestations of sexual behavior dispositions. And the summary concept claim simply doesn't
} 
Objection \#2: Many of the current explanations of sexual orientation are described as ameliorative explanations. ${ }^{45}$ But if you wholly psychologize sexual orientation, or more specifically, "phenomenalize" it, as we do, you can't ameliorate sexual orientation to provide adequate legal protections to sexual minorities. Contra categorical phenomenalism, an explanation of sexual orientation should be politically motivated and reflect injustices and biases in the actual world so as to better protect marginalized groups, not rely on something entirely unobserved by anyone outside of one's own head. ${ }^{46}$

Reply: We see several issues with this objection, issues which invite us to return to our methodological preamble from the start of this paper. First, because we are offering a real definition of the property of being sexually oriented rather than working at the conceptual level, it's hard to see what the ameliorator would have us do. Second, if the problem is that people are treating other people unjustly in virtue of what they perceive people's sexual orientation to be, then the solution is to get those people to stop treating other people unjustly, not to get those people to stop using concepts of sexual orientation.

Of course, however, the problem could be that people's concepts of sexual orientation are themselves objectionable, perhaps not unlike slurring terms might themselves be, as a matter of their essential semantic content, objectionable. Here still, we think the best course of action isn't, per se, to get those people to swap out their objectionable concepts. Rather, it's to get them to see that the negative, objectionable stuff that they associate with the concept of sexual orientation isn't mirrored in the world. For example, suppose someone's concept of male homosexuality is something like "sexual activity only between men that is inherently sinful". But get this person to do a bit of honesty philosophizing and they'll see that there's nothing like sinfulness out there in the world that attaches to homosexuality.

Objection \#3: Relying solely on the phenomenological state of sexual arousal to explain sexual orientation results in too restricted of a view. People can have sex in ways that have nothing to do with arousal. Contra categorical phenomenalism, this means that there is more to sexual orientation than arousal alone.

Reply: This brings us back to an earlier part of our discussion where we alluded to a distinction between sexual preferences and sexual orientation. One sense in which our view conforms to orthodoxy is that we claim that it is part of the subject matter of sexual orientation that it only concerns sexual expression in response to the bundle(s) of features constitutive of manhood, womanhood, etc. rather than expression in response to anything else like e.g., foot shape, hair color, and so on. There is a bit of awkwardness in our acceptance of this constraint, given our emphasis on the features that constitute manhood, womanhood, etc. in our knowledge and ascriptions there of concerning sexual orientation. But we conjecture that the awkwardness is benign, merely an artifact of our not defending explicit views of what constitutes these categories. In the absence of such a defense, it does look arbitrary for us to say e.g., that it's sexual arousal in virtue of the aggressive sensibility that is constitutive of manhood that constitutes one's sexual orientation rather than e.g., foot shape. But all we need for an intelligible distinction between sexual preferences and sexual orientation is for there to be something like the categories of manhood, womanhood, etc. and we're optimistic that there are such categories.

address our explanatory fundamentality objection according to which, to paraphrase, sexual behavior is not prior to sexual thought which is not prior to sexual arousal.

${ }^{45}$ See Dembroff (2016) and Díaz-León (forthcoming).

${ }^{46}$ This objection is inspired by Dembroff's (2016) argument for an ameliorative account of sexual orientation. 


\section{6 | CONCLUSION}

We take ourselves to have accomplished at least two substantial tasks in this paper. The first is providing reason to doubt the dispositionalist orthodoxy about sexual orientation. We did that by giving several extensional objections and an explanatory objection. We also argued that there's just no good way of identifying the circumstances or conditions under which the dispositionalist's preferred dispositions are said to manifest, suggesting that any form of dispositionalism about sexual orientation ought to be rejected. The second task is sketching an alternative to dispositionalism. We did that by introducing, outlining, and defending against objections, categorical phenomenalism, the view that sexual orientation is best understood in terms of our actual feelings of sexual arousal.

\section{O R C I D}

\section{N. G. Laskowski (D) https://orcid.org/0000-0001-8349-8737}

\section{WORKS CITED}

Andler, Matthew (forthcoming). "Sexual Orientation Categories". Ergo.

Andler, Matthew (2021). "The Sexual Orientation/Identity Distinction”. Hypatia:36 (2): 259-275

Arpaly, N. \& Schroeder, T. (2014). In Praise of Desire. Oxford University Press.

Ashwell, Lauren (2010). "Superficial Dispositionalism." Australasian Journal of Philosophy 88:635-653.

Ashwell, Lauren (2013). 'Deep, Dark,... or Transparent? Knowing Our Desires,' Philosophical Studies, 165(1): 245256.

Ayala, Saray (2017): "Sexual Orientation and Choice". Journal of Social Ontology 3:249-265

Bettcher, Talia Mae (2014). "When Selves Have Sex: What the Phenomenology of Trans Sexuality Can Teach Us About Sexual Orientation”. Journal of Homosexuality 61. No. 5, p. 605-620.

Brandt, R. (1970). “Traits of Character: A Conceptual Analysis.” American Philosophical Quarterly 7: 23-37.

Brunning, Luke \& McKeever, Natasha (2020). “Asexuality”. Journal of Applied Philosophy.

Burgess, Alexis, et al. (2020). Conceptual Engineering and Conceptual Ethics. Oxford University Press.

Cappelen, Herman (2018). Fixing Language: An Essay on Conceptual Engineering. Oxford University Press.

Dembroff, Robin (2016). 'What Is Sexual Orientation?' Philosophers' Imprint, 16(3), pp. 1-27.

Diaz-Leon, E. (2016). "Woman as a politically significant term: a solution to the puzzle”. Hypatia 31(2):245-258

Díaz-León, Esa (2017). Sexual Orientation as Interpretation? Sexual Desires, Concepts, and Choice. Journal of Social Ontology 3 (2):231-248.

Díaz-León, Esa (forthcoming). "Sexual Orientations: The Desire View”. K. Maitra \& J. McWeeny (eds) Feminist Philosophy of Mind, Oxford University Press.

Elliot, A. (2017). "Reasons, Dispositions, and Value”. Philosopher's Imprint, 1-17.

Finlay, Stephen \& Laskowski, Nicholas (2017). “Conceptual Analysis in Metaethics,”. In: T. McPherson \& D. Plunkett (eds.), Routledge Handbook of Metaethics.

Finocchiaro, P. (2021). "How to Project a Socially Constructed Sexual Orientation”. Journal of Social Ontology https: //doi.org/10.1515/jso-2021-0005.

Finocchiaro, P. (manuscript). "Sexual Orientation and Intrinsic Masking”. 1-19. Draft available at http:// peterfinocchiaro.com/wp-content/uploads/2020/08/IntrinsicMaskingAndSexualOrientation2.0.pdf

Fogal, D. (2016). Review of Stephen Finlay's. Confusion of Tongues: A Theory of Normative Language, Ethics 127, October 2016: 281-288.

Foucault, M. (1980). The History of Sexuality, Volume One: An Introduction. Vintage Books.

Howard, N. (2021a). "One Desire Too Many” Philosophy and Phenomenological Research 102, no. 2. (2021): 302-317.

Howard, N. (2021b). "Moral Fetishism and a Third Desire for What's Right". Journal of Ethics and Social Philosophy 20(3).

Johnston, Mark. (1992). "How to Speak of the Colors". Philosophical Studies 68:221-263.

Laskowski, N. (2020). "Moral Constraints on Gender Concepts”. Ethical Theory and Moral Practice, 23, 39-51.

Lewis, David. (1973). Counterfactuals. Oxford: Blackwell. 
Miller, C. (2014). Character and Moral Psychology. Oxford University Press.

Miller, C. (2021). Honesty: The Philosophy and Psychology of a Neglected Virtue. Oxford University Press.

Pelham, Brett (2004). "Affective forecasting: The perils of predicting future feelings". Psychological Science Agenda. American Psychological Association.

Saul, J. (2012). Politically significant terms and philosophy of language: methodological issues. In: In Out from the Shadows: Analytical Feminist Contributions to Traditional Philosophy, ed. Oxford University Press, Sharon Crasnow and Anita Superson. Oxford

Schneider, Margaret, et al. (2002). "Implementing the Resolution on Appropriate Therapeutic Responses to Sexual Orientation: A Guide for the Perplexed”. Professional Psychology: Research and Practice, American Psychological Association Vol. 33, No. 3, 265-276.

Shah, Sonali (2017). "Disabled People Are Sexual Citizens Too: Supporting Sexual Identity, Well-being, and Safety for Disabled Young People". Frontiers in Education, Vol 2.

Shope, Robert K (1978). “The conditional fallacy in contemporary philosophy”. Journal of Philosophy 75 (8):397-413.

Smith, Michael. (1994). The Moral Problem. Blackwell.

Stein, Edward (1999). The Mismeasure of Desire: The Science, Theory, and Ethics of Sexual Orientation. Oxford University Press.

Stock, Kathleen (2019). "Sexual Orientation: What is it?" The Aristotelian Society. Proceedings of the Aristotelian Society, Vol. cxix, Part 3.

Wedgwood, Ralph (forthcoming). "Ethical Naturalism, Non-naturalism, and In Between".

Wiggins, J. (1997). "In Defense of Traits," in Handbook of Personality Psychology. Ed. R. Hogan, J. Johnson, and S. Briggs. San Diego, CA: Academic Press, 95-115. Originally presented in 1973.

Wilkerson, William S (2009): “Is It a Choice? Sexual Orientation as Interpretation”. Journal of Social Philosophy 40. No. 1, p. 97-116.

Wilkerson, William S (2013): “What is 'Sexual Orientation'?”. In: Nicholas Power, Raja Halwani, and Alan Soble (Eds.): The Philosophy of Sex: Contemporary Readings, 6th edition. Lanham, MD: Rowman and Littlefield, p. 195-213.

Zeman, D. (2020). "Subject-Contextualism and the Meaning of Gender Terms". Journal of Social Ontology, 6(1), 69-83.

How to cite this article: Whitlow, T. R. \& Laskowski, N. G. (2022). Categorical phenomenalism about sexual orientation. Philosophy and Phenomenological Research, 1-16. https://doi.org/10.1111/phpr.12872 